\title{
Running head: VULNERABILITIES IN GRAMMATICAL PROCESSING OF BILINGUALS
}

Investigating vulnerabilities in grammatical processing of bilinguals: Insights from

Basque-Spanish adults and children.

\author{
Marie Pourquié ${ }^{1,2}$, Hugues Lacroix ${ }^{2,3,4}$, Natalia Kartushina ${ }^{1,5}$ \\ ${ }^{I}$ Basque Center on Cognition, Brain and Language \\ ${ }^{2}$ Université de Montréal \\ ${ }^{3}$ IKER UMR-5478 \\ ${ }^{4}$ Université Bordeaux-Montaigne \\ ${ }^{5}$ Department of Psychology, Faculty of Social Science, University of Oslo
}

\begin{abstract}
(max 150)
Bilinguals show a large gap in their expressive-receptive abilities, in both languages. To date, most studies have examined lexical processing. The current study aimed to assess comprehension and production of verb agreement, i.e., grammatical processing, in bilinguals, and to examine the factors that might modulate them: exposure, age and language-specific morphological complexity. Twenty balanced Basque-Spanish bilinguals (10 adults and 10 children) were assessed on comprehension and production of subject-verb agreement in both languages and object-verb agreement in Basque. Twenty age-matched Spanish-dominant Basque-Spanish bilinguals were assessed in Spanish only. The results revealed a consistent gap in Basque in both children and adults, with an advantage for comprehension. In Spanish, a gap appeared in children only, with an advantage for production. The gap size did not vary with the amount of language exposure but with age and morphological complexity, suggesting that these factors modulate bilinguals' grammatical processing.
\end{abstract}

Keywords: Bilingualism, Basque, Spanish, morphological complexity, verb processing, expressive-receptive grammatical gap 


\section{VULNERABILITIES IN GRAMMATICAL PROCESSING OF BILINGUALS}

\section{Introduction}

Studies show that bilinguals have a larger gap between production and comprehension abilities, compared with monolinguals, in both first (L1) and second (L2) languages, with comprehension typically surpassing production (Gibson, Peña, \& Bedore, 2014). However, the majority of previous studies examined vocabulary (lexical) abilities only, with grammatical abilities being merely discussed, if considered at all (Keller, Troesch, \& Grob, 2015). The current study addresses this lacuna in the literature and examines, for the first time, the 'gap' hypothesis for verb grammatical processing in Basque-Spanish bilingual children and adults.

\subsection{Gap between comprehension and production in the language processing of}

\section{bilinguals}

The asymmetry between comprehension and production abilities in bilinguals is commonly called the 'expressive-receptive gap' (see Gibson et al., 2014) and has been attributed to a weakness in lexical-semantic links (Gollan, Montoya, Cera, \& Sandoval, 2008; Gollan et al., 2011). According to the 'language exposure hypothesis' (Keller et al., 2015), bilinguals' lower exposure to each of their languages weakens the lexical-semantic links, affecting production more than comprehension (Gollan et al., 2008). These conclusions, however, stem from the results of solely lexical processing tasks, where participants operated with isolated words in their uninflected forms, for example, the naming and understanding of a verb. (Gibson, Oller, Jarmulowicz, \& Ethington, 2012; Yan \& Nicoladis, 2009). Data from studies examining other qualitatively different linguistic processes, such as morphosyntactic, and of larger linguistic units, such as sentences, are needed in order to better understand the development of comprehension and production abilities in bilinguals (Bohman, Bedore, Peña, Mendez-Perez, \& Gillam, 2010).

A wide body of current research is dedicated to the understanding of the basis of the 


\section{VULNERABILITIES IN GRAMMATICAL PROCESSING OF BILINGUALS}

expressive-receptive gap in bilinguals and the factors that might modulate it. A recent study has examined the role of L1 typology on the degree of gap in bilinguals' L2. Keller et al. (2015) assessed the production and comprehension of sentences in German (L2) in sequential bilingual children (mean age of 3.5 years) with various L1s. The results revealed a consistent gap in bilinguals' L2, irrespective of their L1 family type (e.g., Romance, Germanic, etc.) and the typological distance between their L1 and L2 (e.g., Dutch and German are closer than English and German, all being Germanic languages). The gap size varied with the amount of language exposure to German, irrespective of L1 typology. Although, the results of the Keller and colleagues study are very informative, they do not assess sentence processing in the participants' L1s, and importantly, the verbal structure used in the tasks was very similar across the sentences, which limits the generalizability of the results. Our study further investigates language typology impact on the general expressive-receptive gap in bilinguals by examining verb grammatical processing in Spanish and Basque, the latter having a morphologically more complex agreement paradigm (see Current Study section). The assessment of internal (grammatical) and external (exposure) factors on language expressivereceptive abilities will shed light on language production and comprehension mechanisms (Litcofsky, Tanner, \& van Hell, 2016; Pickering \& Garrod, 2014).

Thus, some studies suggest that the expressive-receptive gap in bilinguals is modulated by language exposure (Ben Zeev S., 1977; Keller et al. 2015; Oller, Pearson, \& Cobo-Lewis, 2007). Also, there are a handful of studies that have examined the role of age on both expressive and receptive abilities. For instance, Gershkoff-Stowe and Hahn (2013), examined the acquisition of new (artificial) words in monolingual English children and adults. The authors reasoned that if age modulated the gap size, then overall adults should perform better than children, with in particular their expressive-receptive gap being smaller. The authors observed that receptive ability (i.e., word comprehension) was better than expressive 


\section{VULNERABILITIES IN GRAMMATICAL PROCESSING OF BILINGUALS}

ability (i.e., word production) in both adults and children, with no group differences in gap size. The authors interpreted this "as evidence that the underlying operations of comprehension and production are fundamentally similar in adults and children" (GershkoffStowe and Hahn, 2013, p. 503) and attributed the gap in both groups to differences in the processing mechanisms involved in lexical receptive and expressive abilities. More data, however, are needed to assess the age hypothesis in processes that go beyond the one-word level (e.g., sentence production and comprehension) and, ideally, in natural language learning contexts.

\subsection{Grammatical processing of verbs in production and comprehension}

Verb processing is particularly vulnerable to language impairment as reported by psycholinguistic studies of language development and disorders. For instance, data from developmental studies show not only that children acquire verbs later than nouns, but that they make more morphological errors with verbs than with words from other grammatical classes (Waxman et al., 2013). In some language syndromes, verb morphology appears to be specifically impaired (e.g., agrammatic aphasia, Bastiaanse, Rispens, Ruigendijk, Rabadán, \& Thompson, 2002; Lapointe, 1985; specific language impairment, Leonard, 2014; Rothweiler, Chilla, \& Clahsen, 2012), with other aspects of verb processing being relatively preserved (e.g., lexical retrieval; Franco, 2014; Pourquié, 2013). However, most studies on verb processing, in both typical and atypical populations, have examined production abilities only, with little or no insight into grammatical verb-agreement abilities (Blom, Vasić, \& Jong, 2014). Moreover, there have been even fewer cross-linguistic studies, although these are highly relevant since a/typical language processing is known to be constrained by language specific morphological properties, which affect both expressive and receptive skills. For instance, the development of verb agreement in typical populations varies with languagespecific morphophonological properties (Legendre et al., 2014; Pérez-Leroux, 2005; 


\section{VULNERABILITIES IN GRAMMATICAL PROCESSING OF BILINGUALS}

Verhagen \& Blom, 2014). There are also language-specific differences in the degree of verb agreement impairment across production and comprehension. In French, producing verb agreement in the plural is more prone to error than producing it in the singular (Franck et al., 2004), whereas the reverse is true in Dutch (Verhagen \& Blom, 2014). In Spanish verb comprehension, plural agreement presents an advantage over singular agreement, presumably because the agreement morpheme is phonologically more salient in the plural than in the singular; consider, hablan vs habla, 'they speak' vs 's/he speaks' (Ågren \& van de Weijer, 2013; Gonzalez-Gomez et al., 2014; Pérez-Leroux, 2005). Investigating verb processing vulnerability to impairment in both comprehension and production, in different languages and in typical bilingual populations, is crucial in order to disentangle language disorders from typical language processing in multilingual settings (Armon-Lotem, de Jong, \& Meir, 2015).

In sum, the above-mentioned studies suggest that language-specific factors might modulate the expressive-receptive abilities in monolingual speakers. However, we lack studies that have examined the role of language-specific factors on the development of grammatical processing in bilinguals, and how external (e.g., language exposure) vs internal factors (e.g., language-specific grammatical properties) affect it. Finally, note that the majority of studies on verb agreement morphology have examined subject-verb agreement (e.g., English, Spanish, Dutch, French). Less is known about object-verb agreement in languages that inflect verbs for object agreement (e.g., Basque).

\subsection{Gap in grammatical processing of verbs in bilinguals: the current study}

The assessment of Basque-Spanish bilinguals allows, from a psycholinguistic perspective, the examination of distinct language-specific grammatical processes within the same individual as Basque and Spanish are geographically close but typologically distant languages. Spanish is a member of the Indo-European language family, whereas Basque is 


\section{VULNERABILITIES IN GRAMMATICAL PROCESSING OF BILINGUALS}

not: it is considered "isolated", i.e. typologically not related to any other language (Hualde \& de Urbina, 2003).

Basque and Spanish differ with respect to the degree of grammatical complexity of verbs, with Basque having the more complex morphological paradigm. While Basque verbs agree with both the subject and the object, Spanish verbs agree with the subject only (see Table 3 and Appendices C and D). This particular feature of Basque allows us to assess verb grammatical processing in object-verb agreement contexts, generating therefore, new insights into verb agreement processing, as to date, most studies have examined subject-verb agreement only.

On the other hand, there are some similarities between Basque and Spanish. For instance, Basque and Spanish are both subject pro-drop languages, which is perfectly suited to the assessment of subject-verb agreement in comprehension (Legendre et al., 2014; Pourquié, 2013). Also, both languages have phonologically more salient forms in plural than in singular subject-verb agreement contexts, which allows the assessment of the phonological salience hypothesis for subject-verb agreement comprehension in Basque and Spanish.

The current study examined, for the first time, the role of exposure, age and morphological complexity in grammatical processing of verb agreement in both production and comprehension in Basque-Spanish bilingual individuals, using, for both languages, a recently developed tablet-based tool: $f L E X^{l}$ (Pourquié, 2015). In addition, in order to better understand the development of the expressive-receptive gap in grammatical processing of Basque-Spanish bilinguals, our study assessed bilinguals of different ages (i.e., in children and adults), in both L1 and L2. We also assessed the expressive-receptive gap in morphosyntactic (grammatical) processing (i.e., beyond lexical processing), in an understudied language pair: Basque-Spanish. Our main objective was to identify vulnerabilities to

\footnotetext{
${ }^{1}$ This study is part of a bigger cross-language and cross-population study on lexical and inflectional processing in French, Basque and Spanish in different countries (Quebec and the Basque Country). The data presented in the current study represent the results of two (out of five) tasks.
} 


\section{VULNERABILITIES IN GRAMMATICAL PROCESSING OF BILINGUALS}

error in typically developing bilingual children and adults performing grammatical tasks in both their languages, here Spanish and Basque. We tested whether there was an expressivereceptive gap and if so, whether it was modulated by (1) the amount of language exposure, (2) speaker's age, and (3) language-specific morphological complexity.

Language exposure in children and adults was measured through questionnaires (see Table 2). Two subgroups were defined: Basque-Spanish balanced, and Spanish-dominant (i.e., more exposed to Spanish) bilingual individuals. We tested four hypotheses (see Table 1 for a summary). Based on the results of recent studies showing that, due to less exposure, bilinguals had larger production-comprehension differences (both in their L1 and L2) than monolinguals, we predicted that the 'gap' size would be bigger in the balanced group (for both languages) than in the Spanish-dominant bilingual group for Spanish, both in children and adults (HYPOTHESIS 1). In addition, assuming that children are still in the process of developing grammatical competence and that they produce more errors than adults, we expected the gap to be bigger in children than in adults, with an advantage for comprehension. Following the language exposure hypothesis, we expected that adults would have been more exposed to both languages and would have a better proficiency than children in both languages, i.e. Basque and Spanish, and in both groups, Spanish-Basque balanced and Spanish-dominant (HYPOTHESIS 2). In line with previous studies on singular and plural subject-verb agreement production and comprehension, which showed that plural agreement is more vulnerable to error than singular agreement in production but not in comprehension, we assumed a larger gap for plural as compared to singular agreement in both Basque and Spanish (HYPOTHESIS 3). Moreover, we tested whether the same holds true for plural versus singular object agreement in Basque in balanced bilinguals only (HYPOTHESIS 4). 


\section{VULNERABILITIES IN GRAMMATICAL PROCESSING OF BILINGUALS}

Table 1. Summary of hypotheses

Role of exposure H1: The balanced Basque-Spanish bilinguals present a bigger expressive-receptive gap in both Basque and Spanish than the Spanish-dominant bilinguals.

Role of age $\quad$ H2: Children present a bigger expressive-receptive gap than adults.

Role of morphological H3: In both Basque and Spanish, a bigger expressive-receptive gap is complexity expected for plural subject agreement than singular subject agreement.

H4: In the Basque language only, a bigger expressive-receptive gap will be observed for plural object agreement than singular object agreement.

\section{Method}

\subsection{Participants}

Forty participants took part in this study, twenty adults and twenty children. They were recruited through the Basque Center on Cognition, Brain and Language (BCBL, Donostia, Gipuzkoa province) database for participant recruitment. All participants completed a questionnaire to get information about their general (e.g., age, gender, education) and linguistic profile (age of acquisition for each language; proficiency and exposure in each language including measures for both oral and written exposure and use, e.g., reading, listening, writing, and speaking, respectively, see Table 2). The lower age limit for children was set at 5; by this age, children seem to have mastered verb processing in both production and comprehension (Johnson et al., 2005) and, therefore, they should be able to perform the tasks of our study. In each group, half the participants were female and half male. All adults 


\section{VULNERABILITIES IN GRAMMATICAL PROCESSING OF BILINGUALS}

and four of the children were assessed at the BCBL and $16^{2}$ out of the 20 children at their school, where the BCBL junior lab is located (Gasteiz, Àlava province). None of the participants reported any history of hearing, vision or language deficits.

In each age group (children and adults), half of the participants $(n=10)$ were balanced Basque-Spanish bilinguals and half were Spanish-dominant Basque-Spanish bilinguals ${ }^{3}$, as revealed by parental reports and by self-ratings, respectively. Three criteria were used to determine the group assignment: age of acquisition, language proficiency and amount of spoken language use. Participants in the balanced group had the following characteristics: (1) acquired both languages at birth (with the mean of 0.5 and 1.2 years old for children and adults, respectively); (2) were highly proficient in both languages with the mean proficiency scores of 7.9 and 7.2 (where 10 is maximum, $p>.1$ ) in children and 9.7 and $9.1(p>.1)$ in adults; and (3) had similar amounts of Spanish and Basque use (42\% and $49 \%$ in children and $57 \%$ and $42 \%$ in adults; see Table 2 for details). Participants in the Spanish-dominant group, on the other hand, had the following characteristics: (1) acquired Spanish at birth $(M=0)$, and Basque at 2.5 and 9.2 years old in children and adults, respectively; (2) mastered Spanish considerably better than Basque in both child ( 7.6 versus 5.7, $p .001)$ and adult $(9.4$ versus $2.25, p<.001)$ groups, and (3) used Spanish more than Basque $(56 \%$ versus $26 \%$ in children and $82 \%$ and $7 \%$ in adults). There were no significant age differences between the BasqueSpanish balanced and Spanish-dominant bilingual children (range 5-10 for both; mean age 7.1 and 7.5, respectively) and adults (range $20-79, M=32.8$; range $21-73, M=39.3$, respectively)

\footnotetext{
${ }^{2}$ Four children did not complete the study; therefore, four other children (matched in age and gender) were recruited and were assessed at the BCBL.

${ }^{3}$ Initially, the project aimed to assess the grammatical processing in bilingual and monolingual speakers of the Basque country, however, this was not possible due to the sociolinguistic situation of the Basque Autonomous Community (BAC) where Spanish coexists with Basque. Although, it is still possible to encounter monolinguallike adult speakers with very low proficiency in Basque, it is hardly possible to find monolingual children, due to recently introduced policies of mandatory education in Basque in public and private child-care centers and schools. Interestingly, in both groups, children reported higher exposure to Basque than adults (26\% vs $10 \%)$. This is probably due to the fact that, in the BAC since 1979, Basque is co-official with Spanish. While in the early 80 s it was only marginally present in people's social life, nowadays it is widely used in education, administration and the media (Hualde \& Zuazo, 2007). That is why currently all inhabitants of the BAC are regularly exposed to Basque, with children having more exposure than adults.
} 


\section{VULNERABILITIES IN GRAMMATICAL PROCESSING OF BILINGUALS}

$(p>.1)$. Note that the participants in the balanced group were assessed in both Basque and Spanish, whereas in the Spanish-dominant group they were assessed in Spanish only, due to their low proficiency in Basque (in particular the adults, i.e., 2.7/10). See Table 2 below for more details on the linguistic and personal background of the participants.

Table 2. Participants' linguistic profile

\begin{tabular}{|c|c|c|c|c|}
\hline & \multicolumn{2}{|c|}{ CHILDREN } & \multicolumn{2}{|c|}{ ADULTS } \\
\hline & $\begin{array}{l}\text { Basque-Spanish } \\
\text { balanced bilingual }\end{array}$ & $\begin{array}{l}\text { Spanish-dominant } \\
\text { bilingual }\end{array}$ & $\begin{array}{l}\text { Basque-Spanish } \\
\text { balanced bilingual }\end{array}$ & $\begin{array}{l}\text { Spanish-dominant } \\
\text { bilingual }\end{array}$ \\
\hline \multicolumn{5}{|l|}{ Age of acquisition } \\
\hline SPANISH & 0.3 & 0 & 1.3 & 0 \\
\hline BASQUE & 0.8 & 2.5 & 1.1 & 9 \\
\hline \multicolumn{5}{|c|}{ Proficiency (where 10 is maximum) } \\
\hline Speak SPANISH & 7.9 & 7.6 & 9.7 & 9.4 \\
\hline Speak BASQUE & 7.2 & 5.7 & 9.1 & 1.8 \\
\hline Understand SPANISH & 7.85 & 7.6 & 9.8 & 9 \\
\hline Understand BASQUE & 7.3 & 5.7 & 9.3 & 2.7 \\
\hline \multicolumn{5}{|c|}{ Exposure to each language (\%) } \\
\hline Use SPANISH & 42 & 54 & 61 & 82 \\
\hline Use BASQUE & 47 & 26 & 36 & 10 \\
\hline Speak SPANISH & 42 & 56 & 57 & 82 \\
\hline Speak BASQUE & 49 & 26 & 42 & 7 \\
\hline Listen SPANISH & 37 & 49 & 57 & 79 \\
\hline Listen BASQUE & 54 & 31 & 38 & 7 \\
\hline
\end{tabular}




\section{VULNERABILITIES IN GRAMMATICAL PROCESSING OF BILINGUALS}

Write SPANISH

Write BASQUE

Read SPANISH

Read BASQUE
55

48

67

28
92

6

81

12

\subsection{Tasks}

In order to assess verb processing from a cross-language and cross-population perspective in bilinguals, we designed a tablet-based language production and comprehension assessment tool, $f L E X$, which is based on the specific linguistic properties of Basque and Spanish. In its current version, it includes five tasks for a total of 160 stimuli. In the present study, only the sentence production and comprehension tasks ( 35 stimuli each) are reported.

\subsubsection{Stimuli}

The stimuli consisted of fifteen action verbs: five intransitive (e.g., to fall down), five transitive (e.g., to build a house) and five ditransitive (e.g., to give a flower) (see Appendices $\mathrm{C}$ and D). There were two agreement conditions, subject-verb and object-verb. The subjectverb condition included the intransitive and transitive verbs (sentences of type 1-4 in Table 3), whereas the object-verb condition included the transitive and ditransitive verbs (sentences of

type 4-7 in Table 3 ). In each condition, each verb was used in $3^{\text {rd }}$ person singular and plural agreement contexts. In total there were 35 sentences ( 7 types x 5 items each), which were used in both sentence comprehension and production tasks. 


\section{VULNERABILITIES IN GRAMMATICAL PROCESSING OF BILINGUALS}

Table 3. Sentences used in the production and comprehension task, classified by transitivity and agreement type. The crucial morphological elements are in bold.

\begin{tabular}{|c|c|c|c|c|c|c|c|c|}
\hline \multicolumn{2}{|c|}{$\begin{array}{l}\text { Type/ } \\
\text { Number } \\
\text { of items }\end{array}$} & \multirow[t]{2}{*}{$\begin{array}{l}\text { Examples of sentences in Basque }(\mathrm{B}) \text { and Spanish }(\mathrm{S}) \text { for } \\
\text { production/comprehension }\end{array}$} & \multicolumn{2}{|c|}{$\begin{array}{l}\text { Subject- } \\
\text { verb }\end{array}$} & \multicolumn{2}{|c|}{$\begin{array}{l}\text { Transitivity } \\
\text { type }\end{array}$} & \multicolumn{2}{|c|}{$\begin{array}{l}\text { Object- } \\
\text { verb }\end{array}$} \\
\hline & & & $\mathrm{S}$ & $\mathrm{Pl}$ & $\operatorname{Tr}$ & Di & $\mathrm{S}$ & $\mathrm{Pl}$ \\
\hline 1 & 5 & $\begin{array}{l}\text { B: Gizona ateratzen da/ Ateratzen da. } \\
\text { S: El hombre sale/ Sale. } \\
\text { The child leaves/ (He) leaves. }\end{array}$ & & & & & & \\
\hline 2 & 5 & $\begin{array}{l}\text { B: Gizonak ateratzen dira/Ateratzen dira. } \\
\text { S: Los hombres salen/ Salen. } \\
\text { The children leave/ (They) leave. }\end{array}$ & & & $\sqrt{ }$ & & & \\
\hline 3 & 5 & $\begin{array}{l}\text { B: Txakurrak hezurra jaten du /Hezurra jaten du. } \\
\text { S: El perro come el hueso / Come el hueso. } \\
\text { The dog eats the bone/ (He) eats the bone. }\end{array}$ & & & & & & \\
\hline 4 & 5 & $\begin{array}{l}\text { B: Txakurrek hezurra jaten dute /Hezurra jaten dute. } \\
\text { S: Los perros comen el hueso / Comen el hueso. } \\
\text { The dogs eat the bone/ (They) eat the bone. }\end{array}$ & & $\sqrt{ }$ & & & & \\
\hline 5 & 5 & $\begin{array}{l}\text { B: Txakurrak hezurrak jaten ditu /Hezurrak jaten ditu. } \\
\text { S: El perro come los huesos / Los come. } \\
\text { The dog eats the bones/ He eats them. }\end{array}$ & & & & & & \\
\hline 6 & 5 & $\begin{array}{l}\text { B: Haurrak txakurrari pilota botatzen dio /Pilota botatzen dio. } \\
\text { S: El niño lanza la pelota al perro/ Le lanza la pelota. } \\
\text { The child throws the ball to the dog/He throws him the ball }\end{array}$ & & & & & & \\
\hline 7 & 5 & $\begin{array}{l}\text { B: Umeak txakurreri baloia botatzen die/ Pilota botatzen die. } \\
\text { S: El niño lanza la pelota a los perros/Les lanza la pelota. } \\
\text { The child throws the ball to the dogs / He throws them the ball. }\end{array}$ & & & & & & \\
\hline
\end{tabular}

Note. The sentence types 1, 2, 3 and 4 were used to assess the role of agreement type on subject-verb processing (singular, i.e., types 1 and 3, versus plural, i.e., types 2 and 4). The sentence types 3, 5, 6 and 7 were used to assess the role of agreement type on object-verb processing (singular, i.e., types 3 and 6, versus plural, i.e., types 5 and 7). $\mathrm{S}=$ singular, $\mathrm{Pl}=$ plural, $\mathrm{In}=$ intransitive, $\mathrm{Tr}=$ transitive, $\mathrm{Di}=$ ditransitive.

\subsubsection{Sentence production task}

The sentence production task aimed to assess verb processing in a sentential context and to examine whether production difficulties increased as a function of agreement type (singular and plural) in subject-verb (both in Spanish and Basque) and object-verb (in Basque only) agreement contexts. The visual stimuli used in the production task were thirty-five pictures illustrating the above-mentioned sentences (see Table 3). Plural was always depicted 


\section{VULNERABILITIES IN GRAMMATICAL PROCESSING OF BILINGUALS}

by the presence of two characters or objects (e.g., the picture depicted two boys sleeping in a bed to elicit the sentence 'They sleep'). The pictures were designed to elicit sentences with no embedded structure to avoid difficulties related to the processing of syntactically complex sentences. Also, participants were instructed to produce the present simple tense (e.g., 'The dog eats the bone', not the progressive form, e.g., 'The dog is eating the bone'). The present simple tense forces verb inflection of different agreement types, while the progressive form always involves an intransitive structure of the type "to be doing", which requires agreement with the subject only. Prior to the experiment, all pictures were carefully examined by a group of linguists, speech therapists and neuropsychologists. All the actions/verbs used in sentence production and comprehension tasks were recognized, on average, in $80 \%$ of cases. ${ }^{4}$

\subsubsection{Sentence comprehension task}

The sentence comprehension task aimed to assess the understanding of inflected verbs. The stimuli consisted of the same 35 pictures used in the production task and additional 105 distractor-pictures. The distractor pictures were carefully designed in a way such that each action verb had three matching distractors: lexical, grammatical and mixed. For example, for the target sentence '(The dog) eats (a bone)' the distractor-pictures depicted respectively: '(one dog) burying a bone', '(Two dogs) eating a bone' and '(two dogs) burying a bone' (see Figure B2 in Appendix B). Each target picture was displayed simultaneously with the corresponding three distractors. Thirty-five language-matching auditory stimuli were recorded for this task. For that, one native speaker of Basque (the first author) and one native speaker of Spanish, matched on age, gender and pitch contour, read the list of thirty-five sentences used in the comprehension task (see Appendices C and D). The structure of the sentences was the same as in the production task (i.e., in the present simple tense), with the exception of the

\footnotetext{
${ }^{4}$ An item/error analysis revealed that some verb items were consistently substituted by other related verbs : for example, 'to throw the ball' (bota, lanzar) was replaced by 'to play' by $40 \%$ of children and $30 \%$ of adults in Basque (jolastu) and by $30 \%$ of children and $40 \%$ of adults in Spanish (jugar). Similarly, 'to leave' was replaced by agur esan 'to say goodbye' by $50 \%$ of Basque adults. In the Limitations section, we aver that these stimuli require further control in future studies.
} 


\section{VULNERABILITIES IN GRAMMATICAL PROCESSING OF BILINGUALS}

subject pronouns, which were omitted (exploiting the pro-drop parameter) so participants could only rely on verb agreement morphology.

\subsection{Procedure}

Participants were tested individually in a testing room within one session. The examiner was present in the room and gave the instructions. Since the same sentences were used in sentence production and comprehension tasks, the order of tasks was fixed with the production being first. Two one-week interval sessions (one for each language) were required for the balanced bilingual group; the order of languages was counter-balanced.

In the sentence production task, on each trial, one picture of 2560 by 1600 pixels illustrating an action (see Appendix B) appeared on the screen. Participants were instructed to describe the picture making a full sentence in the present simple tense (e.g., 'The dog eats the bone'; see instructions in Appendix A). In order to elicit the present simple tense, the examiner would prompt participants by asking, for example "What does this dog do every day?". There was no timeout; once participants gave their answer, the examiner passed on to the next stimulus by changing the image on the screen. Participants' answers were recorded through the tablet's built-in microphone into 32 bit, $8000 \mathrm{~Hz}$ AMR-NB files.

In the sentence comprehension task, for each stimulus, participants saw four pictures on the screen (the target verb and the three distractors, see Appendix B), and heard a concurrent one-sentence description of the target picture (see Appendices C and D for the full list of audio stimuli) through the tablet's speakers. Participants were instructed to select among the pictures the one corresponding to the sentence they heard and to touch it on the screen; then the next stimulus followed. Participants' responses were saved in an XML filefor later scoring with a 1 for a correct answer and different error codes according to the error type (lexical, grammatical or mixed distractor) for wrong answers. Before each task, three 


\section{VULNERABILITIES IN GRAMMATICAL PROCESSING OF BILINGUALS}

practice stimuli were provided to ensure that participants understood the instructions (see Appendix A).

\section{Results}

\subsection{Data pre-processing}

Data from the production and comprehension tasks were pre-analyzed. Participants' verbal responses in the production task were collected and checked for accuracy manually by the first author: correct answers, whereby the target verb was produced with the accurate inflection, were noted as ' 1 '; utterances with the progressive form were also scored as correct, although participants were prompted to use the present simple tense. This is because they were grammatically correct and used the appropriate target lexical verb. The use of a related verb/verbal phrase (e.g. to play instead of to throw the ball), even if grammatically correct, was classified as a 'related verb error' and was scored zero, because it reflected processing of a qualitatively different grammatical structure and could not be directly compared to the results in the comprehension task. Other answers (e.g., incorrect or omitted verbs, and grammatical errors, e.g., the target word with wrong inflection) were considered incorrect, and were noted as ' 0 '. There were $13 \%$ errors $(4 \%$ of them were 'related-verb' errors, see Appendix E). Then, a mean accuracy score was computed for each subject, modality, language, sentence agreement type and verb type. The analyses were performed separately for the processing of subject-verb (sentence types 1-4) and object-verb (sentence types 3, 5, 6 and 7) agreement.

\subsection{Subject-verb agreement in Basque and Spanish}

This analysis aimed to assess the role of exposure (H1), age (H2), and morphological complexity (H3) on the expressive-receptive gap size in balanced and Spanish-dominant Basque-Spanish bilinguals for subject-verb agreement. Statistical analyses were run using the 


\section{VULNERABILITIES IN GRAMMATICAL PROCESSING OF BILINGUALS}

R software package (R Core Team, 2013). Mixed effects logistic models were used to analyze the data (lme4 package, Bates, Mächler, Bolker, \& Walker, 2015). The main effect and interaction significance was tested by performing the anova function on the model in question. When multiple comparisons were necessary, the lsmeans function implemented in the lsmeans package of the R software was used (Lenth, 2016); Tukey method for p-value adjustment was applied.

3.2.1 Overall results on comprehension and production performance

Before testing the hypothesis on the gap size in the processing of subject-verb agreement across languages and populations, it was important to establish that there was a gap, i.e., that there were differences in performance between comprehension and production tasks in Basque-Spanish balanced and Spanish-dominant children and adults. For that, mean accuracies were fitted to a mixed effects logistic model; the effects of Modality (comprehension vs production), Language group (Basque, Spanish balanced [SpanishB] vs dominant [SpanishD]) and Age (children vs adults) and their interactions were included as fixed factors and by-subject intercept was included as a random factor.

The results revealed a significant effect of Language group $(F=3.47, p=.04)$, with Basque having lower accuracy $(88 \%)$ as compared to $\operatorname{SpanishB}(95 \%)(t=-2.6, p=.03$, there was no difference between Basque and SpanishD or between the two Spanish groups (all $p>$ $.1)$. There was a significant effect of $\operatorname{Age}(F=19.6, p<.001)$ with children having overall lower performance $(87 \%)$ than adults $(97 \%)$. The interactions Modality by Language group ( $F$ $=18, p<.001)$ and Modality by Age $(F=10.2, p=.001)$ were also significant, demonstrating that the gap between the modalities varied across languages and age groups. In particular, in Basque there was a clear advantage for comprehension over production $(10 \%$ difference, $F=$ $5.58, p<.001)$, whereas in both Spanish groups, the $3 \%$ advantage for production was not significant $(F=-1.08, p=.07)$ (see Figure 1). In children, there were no overall differences 


\section{VULNERABILITIES IN GRAMMATICAL PROCESSING OF BILINGUALS}

between comprehension and production modalities ( $85 \%$ and $87 \%, p>.1)$; however, in adults there was an advantage for comprehension ( $99 \%$ vs $95 \%, F=3, p=.01)$, which is likely due to poorer production in Basque (86\%); this possibility was tested further. The effects of Modality and other interactions were not significant $(p>.1)$.
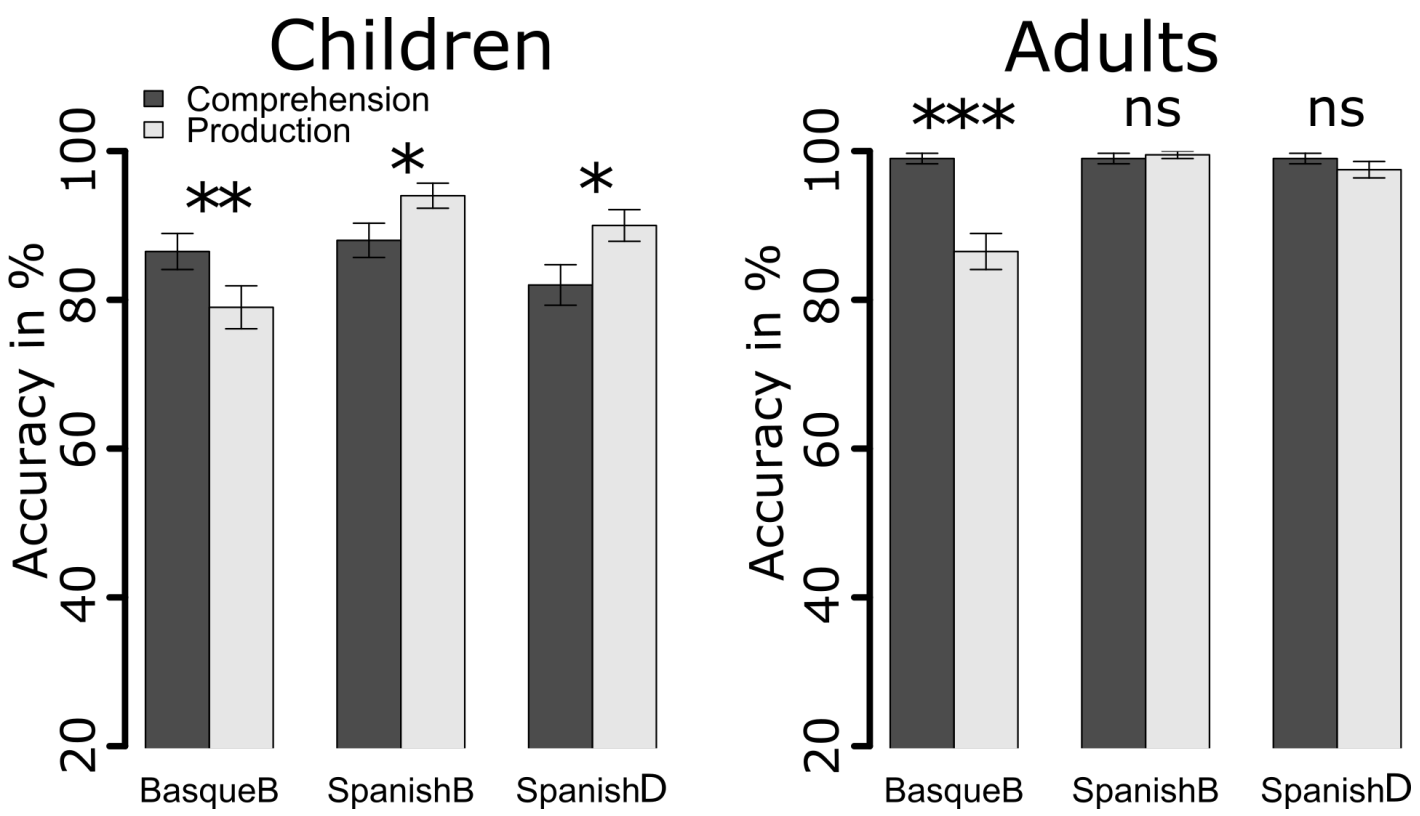

Figure 1. Accuracy in the processing of subject-verb agreement forms in Basque-Spanish balanced (B) and Spanish-dominant (D) bilingual children and adults for Basque and Spanish. The y-axis represents the percentage of accurate responses. Asterisks denote significant results.

Paired comparisons were performed for each language and age group in order to establish the existence of a gap between comprehension and production in each tested group (as postulated in the hypotheses). In children, the results revealed a significant Modality effect, i.e., a gap, in all Language groups. Note, however, that the gap scores in Basque revealed better performance in comprehension ( $86 \%$ vs $79 \%, F=2.9, p=.003$ ), whereas in both Spanish groups they revealed better performance in production ( $94 \%$ vs $88 \%, F=-2.3$, $p=.02$, in SpanishB, and $90 \%$ and $82 \%, F=-3.1, p=.002$ in SpanishD) (Figure 1 and 2). In 


\section{VULNERABILITIES IN GRAMMATICAL PROCESSING OF BILINGUALS}

adults there was an advantage for comprehension in Basque only ( $99 \%$ vs $86.5 \%, F=4.9$, $p<.001$ ); there was no difference between the two modalities (no gap, all $p>.1$ ) in SpanishB (99\% vs 99.5\%) and SpanishD (97.5\% vs 99\%), meaning that balanced and Spanish-dominant adult bilinguals had equal ceiling performance in both production and comprehension tasks in Spanish, whereas they showed a vulnerability to error in production in Basque. Therefore, due to ceiling performance in both Spanish comprehension and production tasks (and hence, absence of gap) in adult groups (Figure 1, right panel), their data for Spanish were excluded from further analysis.

The second analysis aimed to compare the gap size in those groups who showed significant gaps between comprehension and production modalities, namely, children in all language groups and adults in Basque only. For that, for each subject of the aforementioned groups, we computed a gap score for each verb type (intransitive, transitive, ditransitive), agreement type (singular/plural subject or object), and language. It was operationalized as a difference between the comprehension and production mean accuracies. Therefore, a score of zero meant that there was no difference between the two modalities (no gap), a positive score, e.g., ' 10 ', indicated a $10 \%$ advantage for comprehension, whereas a negative score, e.g., '-10', referred to a $10 \%$ advantage for production. In our data the gap varied from -80 to 80 .

Overall, the results revealed that (1) both child and adult bilingual groups performed better in Spanish than in Basque; (2) there was an advantage for comprehension in Basque, but a slight advantage for production in Spanish, and (3) in children, there was a gap in all Language groups, whereas in adults the gap was observed in Basque only.

\subsubsection{Role of exposure, age and morphological complexity on the gap size}

To make the analyses and the interpretation more meaningful, we performed two separate statistical models: first, in order to test the role of Exposure (H1), we tested whether 


\section{VULNERABILITIES IN GRAMMATICAL PROCESSING OF BILINGUALS}

the gap size varied across the Language groups in children (Basque, SpanishB and SpanishD). Second, in order to test the role of Age (H2), we compared the gap size, in Basque only, between children and adults (recall, there was no gap in adults in Spanish). The p-value was adjusted using Bonferroni method and was set to .025 . In both models we also included Agreement as one of the fixed factors to test whether the gap size varied between plural and singular agreement across different languages (H3). The gap score was fitted to a mixed effects logistic model. In the first model the effects of Language group, Agreement (singular vs plural) and their interactions were included as fixed factors. In the second model, the effects of Age, Agreement and their interactions were included as fixed factors. The random structure included by-subject random intercepts in both models.

In children, the results indicated that there was a significant effect of Language group $(F=6.5, p=.001)$ with higher gap score in Basque $(M=7.5 \%$, representing better comprehension than production), as compared to $\operatorname{SpanishB}(M=-6 \%, t=2.9, p=.03)$ and SpanishD $(M=-8 \%, t=3.3, p=0.006)$; both showed an advantage for production (i.e., negative values, see Figure 2). There were no difference in the gap size between SpanishB and SpanishD $(p>.1)$, which is at odds with H1. However, as predicted for subject-verb agreement in $\mathrm{H} 3$, there was a significant effect of Agreement $(F=8.4, p=.004)$ with the plural having an advantage in comprehension (3.3\%) and the singular having an advantage in production (-7.6\%). The Language group by Agreement interaction was not significant $(p>.1)$ (Figure 2, left panel). Mean accuracies are presented in Table 4. Comparison for Basque between Basque-SpanishB bilingual adults and children revealed no effect of Age or Agreement $(p>.1)$, which is at odds with H2. Although, numerically, the gap size was similar between the two age groups in plural agreement and it was bigger in adults (14\%) than in children (2\%) in singular agreement (Figure 2, right panel and Table 4), the Age by 


\section{VULNERABILITIES IN GRAMMATICAL PROCESSING OF BILINGUALS}

Agreement interaction was not significant; in all likelihood this was due to the large variability in the gap in children in both agreement types (from $-80 \%$ to $80 \%$ ).

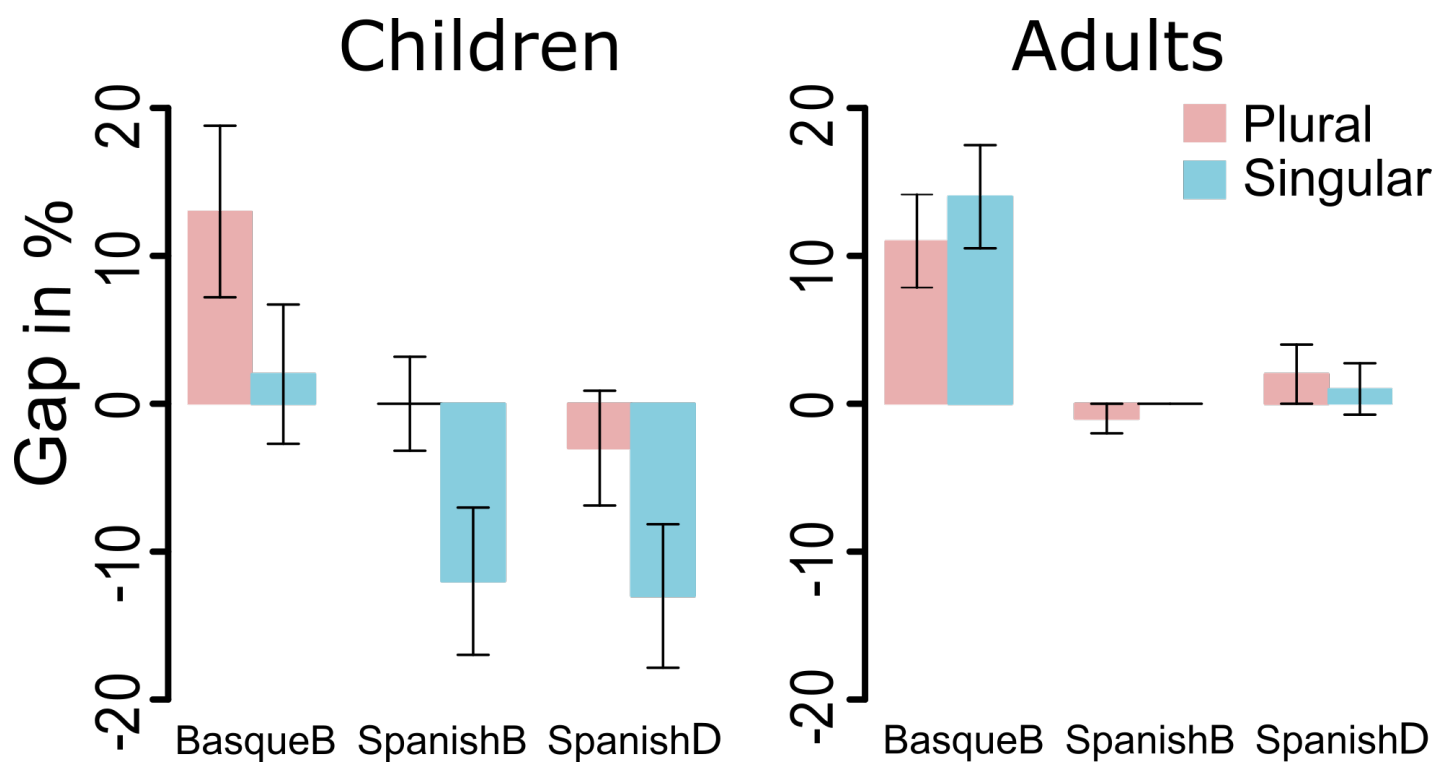

Figure 2. The size of the gap between speech comprehension and production for processing of singular and plural forms of subject-verb agreement in Basque-Spanish balanced bilingual (BasqueB and SpanishB) and Spanish-dominant bilingual (SpanishD) adults and children. Positive and negative values indicate better performance in comprehension and production respectively. Data on adults' processing in both Spanish groups are given for comparative purposes.

Table 4. Mean accuracy (percentage of correct answers) and standard deviation for the processing of subject-verb agreement forms in singular and plural contexts, for Basque and Spanish in Basque-Spanish balanced (B) and Spanish-dominant (SpanishD) bilingual children and adults. 


\begin{tabular}{|c|c|c|c|c|c|c|c|}
\hline \multirow[b]{2}{*}{ Age } & \multirow[t]{2}{*}{ Modality } & \multicolumn{2}{|c|}{ Basque } & \multicolumn{2}{|c|}{ SpanishB } & \multicolumn{2}{|c|}{ SpanishD } \\
\hline & & Plural & Singular & Plural & Singular & Plural & Singular \\
\hline \multirow[t]{2}{*}{ Children } & Comprehension & $87(34)$ & $86(35)$ & $95(22)$ & $81(40)$ & $89(31)$ & $75(44)$ \\
\hline & Production & $74(44)$ & $84(37)$ & $95(22)$ & $93(26)$ & $92(27)$ & $88(33)$ \\
\hline \multirow[t]{2}{*}{ Adults } & Comprehension & $99(10)$ & $99(10)$ & $98(14)$ & $100(0)$ & $99(10)$ & $99(10)$ \\
\hline & Production & $88(32)$ & $85(35)$ & $99(10)$ & $100(0)$ & $97(17)$ & $98(14)$ \\
\hline
\end{tabular}

In summary, for subject-verb agreement processing in children, the results revealed (1) no difference in gap size in Spanish between the Basque-Spanish balanced and Spanishdominant bilingual children, i.e., no effect of Exposure, and (2) an overall effect of Agreement with the advantage of plural agreement in comprehension and of singular agreement in production. For subject-verb agreement in Basque, the results showed no difference in gap size between adults and children, i.e., no effect of Age with the plural agreement; however, with the singular agreement the gap was bigger in adults than in children.

\subsection{Object-verb agreement in Basque}

This analysis assessed the role of morphological complexity on object-verb agreement processing (singular vs plural) in Basque, in comprehension and production, only in BasqueSpanish balanced bilingual adults and children (H4). A similar procedure to the subject-verb agreement analyses was applied. First, we analyzed mean accuracies in comprehension and production for both groups, and then computed the gap score for each subject and submitted it 


\section{VULNERABILITIES IN GRAMMATICAL PROCESSING OF BILINGUALS}

to mixed model analysis. Similar (to subject-verb agreement) three-step analyses were applied to compute the significance values.

The following model was used to analyze participants' performance (mean accuracy) in comprehension and production tasks: the fixed structure included Modality (comprehension vs production), Age (children vs adults), Agreement (singular vs plural) ${ }^{5}$ and their interactions, whereas the random structure included by-subject intercepts. There was a significant effect of Age $(F=13.7, p=.002)$, Modality $(\mathrm{F}=20, p<.001)$ and Agreement $(F=8.5, p=.004)$, indicating that (1) children had overall lower performance $(74 \%)$ than adults $(93 \%),(2)$ the comprehension task was realized better $(90 \%)$ than production $(76 \%)$, and (3) singular agreement yielded better results (88\%) than plural agreement (79\%). The Population by Agreement interaction $(F=4.5, p=.04)$ indicated higher accuracy in the singular $(81.5 \%)$ than in the plural $(65.5 \%)$ in children $(t=-3.5, p<.001)$, but there was no difference in accuracy between the two types of agreement in adults $(94 \%$ and $91.5 \%, p>.1)$. The Modality by Agreement interaction $(F=9.4, p=.003)$ meant higher accuracy in the singular than in the plural in production $(85.5 \%$ vs $65.5 \%)(t=-4.2, p<.001)$, but no difference in accuracy between the two in comprehension $(90 \%$ and $91 \%, p<.1)$. The triple Age by Modality by Agreement interaction was marginally significant $(F=3.8, p=.05)$

(Figure 3). Paired comparisons revealed an advantage for comprehension for plural agreement in both children and adults $(t=4.8, p<.0001$ and $t=2.6, p=.008)$. For singular agreement, there was no difference between the two modalities in children $(p>.1)$, yet there was a marginally significant advantage for comprehension $(t=1.6, p=.1)$ in adults.

\footnotetext{
${ }^{5}$ Due to our straightforward hypotheses and low number of group comparisons (as compared to the analyses on subject-verb agreement), the effect of Agreement was included into the analyses on accuracy. Note, that when excluded, the results remain very similar to those obtained with the effect of Agreement included.
} 


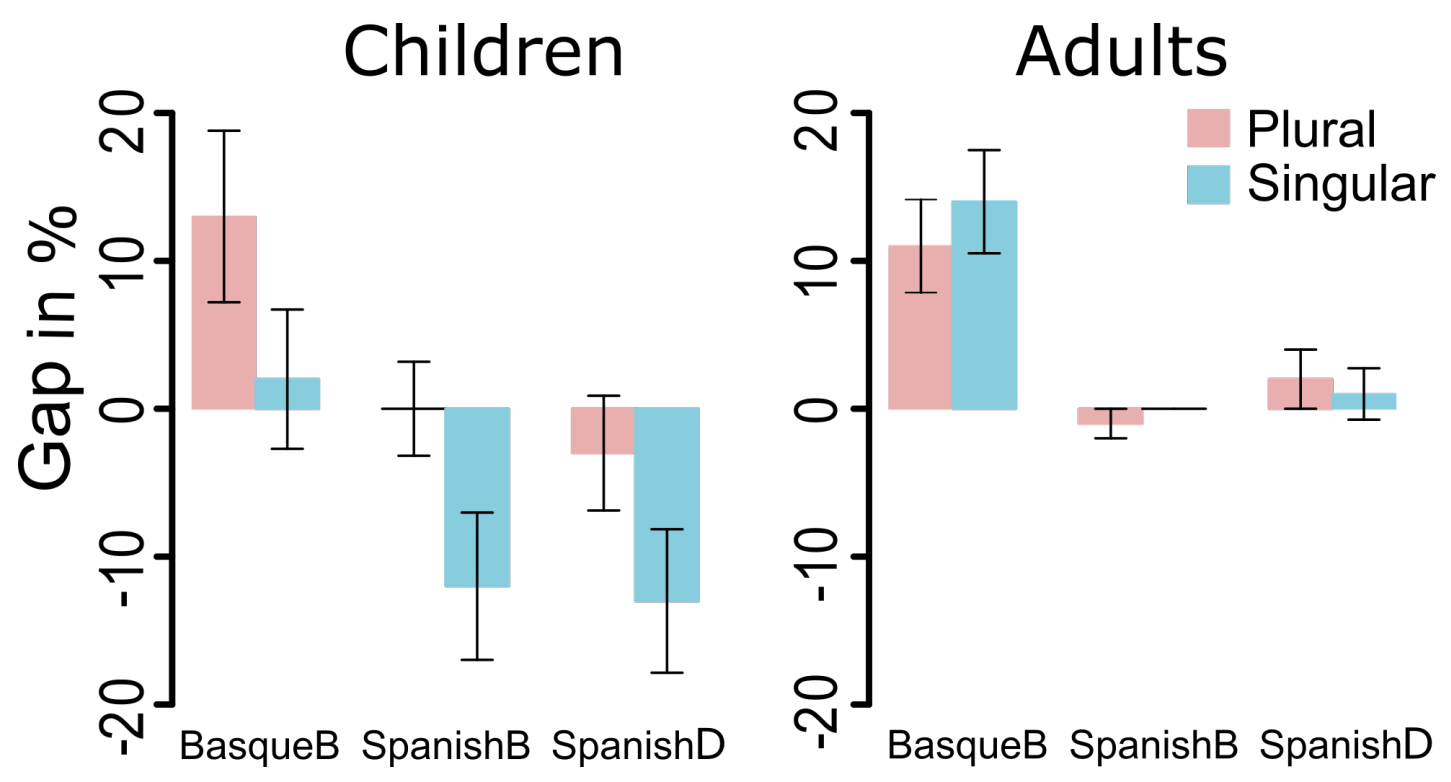

Figure 2. The size of the gap between speech comprehension and production for processing of singular and plural forms of subject-verb agreement in Basque-Spanish balanced bilingual (BasqueB and SpanishB) and Spanish-dominant bilingual (SpanishD) adults and children. Positive and negative values indicate better performance in comprehension and production respectively. Data on adults' processing in both Spanish groups are given for comparative purposes. 


\section{VULNERABILITIES IN GRAMMATICAL PROCESSING OF BILINGUALS}
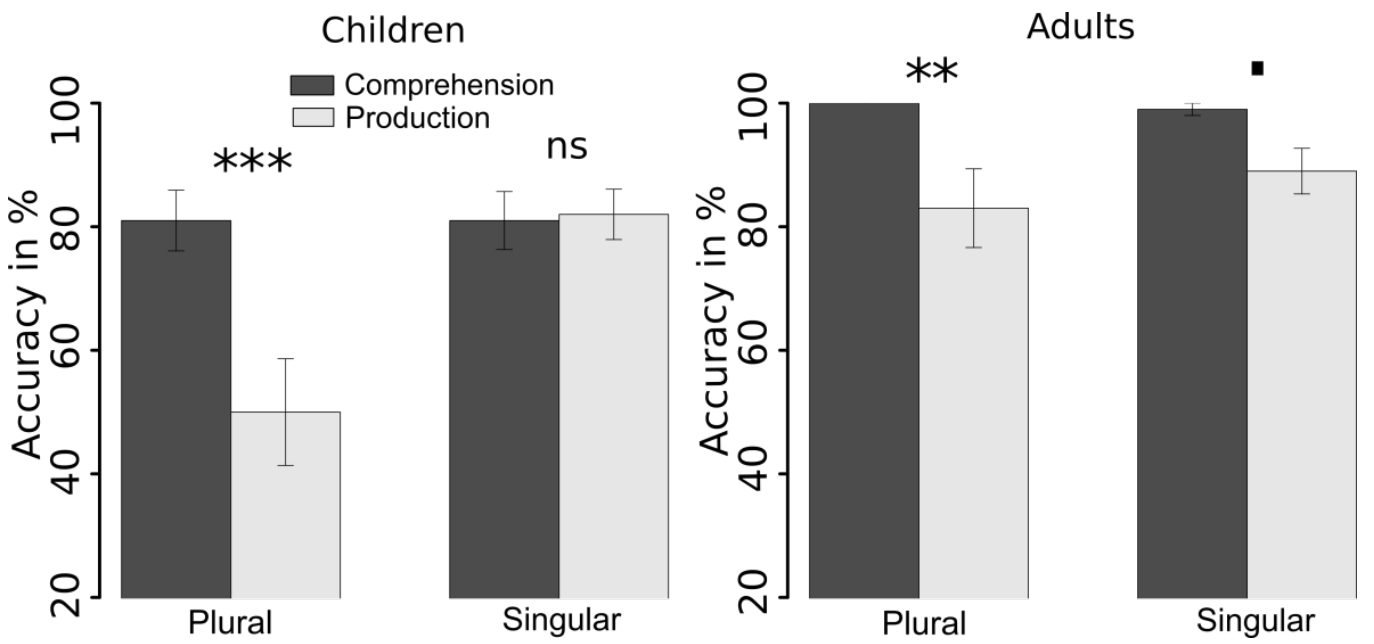

Figure 3. Accuracy in the processing of Basque object-verb agreement forms in singular and plural contexts in bilingual Basque-Spanish children and adults. The y-axis represents the percentage of accurate responses. The asterisks denote significant results, the dot corresponds to $p=.1$.

The next type of analysis tested whether the gap size varied across agreement type and/or age group. The fixed factors in this model were Age (children vs adults), Agreement (singular vs plural) and Age by Agreement interaction. The random structure included bysubject random intercepts. There was a significant Agreement effect $(F=10.4, p=.002)$, with the gap being larger in the plural (24\%) than in the singular (5\%). The Age effect was not significant $(p>.1)$, suggesting that bilingual children and adults have similar gap size between comprehension and production for object-verb processing in Basque. However, the Agreement by Age interaction was significant $(F=4.2, p=.04)$. Paired comparisons revealed a significant difference between singular and plural agreement in children $(t=3.75$, $p<0.001$ ), with the singular having smaller (or practically, no gap $(-1 \%)$ ) than the plural (31\%), but no significant gap in adults $(10 \%$ and $17 \%, p>.1)$ (see Figure 4$)$. 


\section{VULNERABILITIES IN GRAMMATICAL PROCESSING OF BILINGUALS}

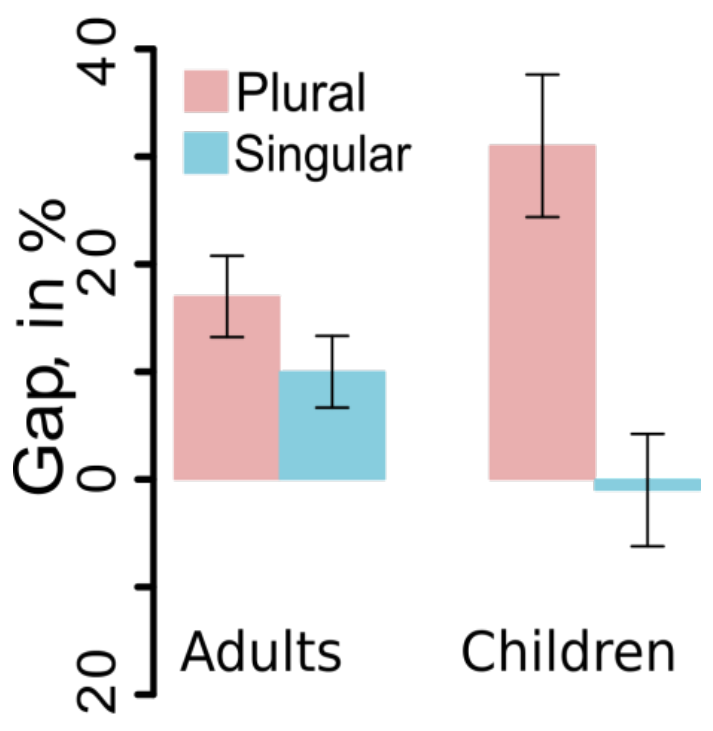

Figure 4. The size of the gap between comprehension and production for processing of objectverb agreement in Basque in singular and plural in Basque-Spanish bilingual adults and children. Positive and negative values indicate better performance in comprehension and production, respectively.

In summary, for object-verb agreement in Basque, the results revealed (1) lower performance in children than adults; (2) higher accuracy in comprehension than production, and (3) higher accuracy in singular agreement. We did not observe a difference in gap size between adults and children, i.e., no Age effect, but a significantly bigger gap in the plural than in the singular, was observed in children but not in adults. The latter shows that, plural object-verb agreement production is more vulnerable to error than singular object verb agreement in children.

\section{Discussion.}

\subsection{Role of exposure (subject-verb processing in Spanish and Basque)}

Bilinguals are less exposed to each of their languages as compared to monolinguals. The language exposure hypothesis (see Keller et al., 2015) assumes that less exposure leads to a larger gap in expressive-receptive abilities, with an advantage for comprehension. In our 


\section{VULNERABILITIES IN GRAMMATICAL PROCESSING OF BILINGUALS}

study, we tested this hypothesis in Basque-Spanish balanced and Spanish-dominant bilingual adults and children. Recall that the Spanish-dominant bilinguals had 18\% more exposure to Spanish than the balanced group. The language exposure hypothesis predicted that balanced bilinguals would have poorer performance in Spanish than Spanish-dominant bilingual participants. In addition, in the balanced bilingual group, the gap in Spanish should be larger than in Basque due to reported lower exposure to Spanish (52\% vs 42\%).

For subject-verb agreement in Spanish, there was no difference in gap size between balanced and Spanish-dominant participants. In particular, the results revealed a ceiling performance in both bilingual adult groups $(>95 \%$ of correct responses in both production and comprehension tasks) with an average non-significant gap of $2 \%$. Both bilingual children groups showed a gap, but there was no difference in size between the groups. The lack of difference in gap size between balanced and Spanish-dominant bilinguals (both children and adults) is at odds with the language exposure hypothesis that predicts a larger gap in less exposed listeners. In our study, the lowest exposure to Spanish, reported for balanced bilingual children, was of $37 \%$ in listening (see Table 2), which might not be low enough to hinder grammar acquisition. Note that, although Basque is the primary language of schooling, Spanish is widely present in daily life, which guarantees regular contact with Spanish. Our results suggest that low but regular language exposure supports the acquisition of subject-verb agreement structures. However, more studies are needed to understand the role of exposure on language acquisition in bilinguals.

For Basque, adults showed a remarkable expressive-receptive gap with an advantage for comprehension, which is in line with the language exposure hypothesis prediction of a larger gap in Basque as compared to Spanish. However, this gap cannot be fully attributed to low grammatical abilities of balanced Basque-Spanish bilinguals, because, as revealed by additional analysis, the majority of errors were lexical -i.e. related verb errors- and not 


\section{VULNERABILITIES IN GRAMMATICAL PROCESSING OF BILINGUALS}

grammatical. Therefore, the current results do not present strong evidence in favor of the language exposure hypothesis in bilingual adult grammatical processing either. On the other hand, although our bilingual children reported slightly higher exposure to Basque than to Spanish, they exhibited a notable expressive-receptive gap in verb processing in Basque with production being weaker than comprehension. The larger gap in children can be attributed to, at least, two related factors: (1) lower Basque proficiency (in spite of high exposure) and (2) higher morphological complexity of Basque as compared to Spanish, leading to impoverished production in Basque. The error analysis of the comprehension task showed only slightly more lexical errors for Basque than for Spanish (see Appendix F), suggesting that bilingual children overall proficiency in Basque was comparable to that in Spanish. However, their low performance in production suggests that balanced bilingual children might need more practice (and/or exposure) to generalize this knowledge to grammatical production.

In summary, our results suggest that, despite relatively high amounts of language exposure ( $>50 \%)$, bilingual children-but not adults-experience difficulties in acquiring the agreement structures of a morphologically complex language; yet, for a morphologically less complex language, they show more robust grammatical competence, even though they have had less (but regular) exposure to it.

\subsection{Role of age (adults and children)}

Recently, it has been suggested that age does not modulate the amount of expressivereceptive gap in lexical (vocabulary) processing in monolinguals. In Gershkoff-Stowe \& Hahn's study (2013), monolingual children and adults exhibited the same gap size, with an advantage for comprehension. In our study, we tested this hypothesis for subject-verb agreement (i.e., beyond lexical processing) in bilingual Basque-Spanish adults and children. We expected adults to perform better and to exhibit a smaller gap than children. 


\section{VULNERABILITIES IN GRAMMATICAL PROCESSING OF BILINGUALS}

Our results revealed an expressive-receptive gap in all Language groups in children and in adults only in the balanced bilingual group and only in Basque. In children, in the Spanish groups there was an advantage for production (with no difference between balanced and Spanish-dominant bilinguals, see Figure 2), whereas in the Basque group there was an advantage for comprehension. In subject-verb agreement contexts, as expected, children performed poorer than adults, with the gap being $17 \%$ larger than in adults.

In adults, the results revealed an expressive-receptive gap in balanced bilinguals only, with an advantage for comprehension, and this only when tested in Basque. An error analysis revealed that these results were due to lexical but not grammatical errors (i.e., participants' production was grammatically correct relative to the target verb) but the Basque-Spanish balanced adult bilingual group had acquired subject-verb agreement in Basque. However, the balanced bilingual children exhibited notable difficulties in subject-verb agreement processing. In object-verb agreement processing, the results revealed a significantly bigger gap in the plural than in the singular in children but not in adults (see section 3.3, Figure 4), suggesting that the acquisition of the grammatical structure in a morphologically complex language, here Basque, requires more practice (and input) than is possible for children of 5-10 years old. This also suggests that other factors (e.g., morphological complexity, see next section) interfere with the expressive-receptive grammatical abilities of bilinguals (also see Anderson, Giezen and Pourquié, to appear).

Our results for Spanish, where children showed a bigger expressive-receptive gap than adults, with an advantage in production, suggest that 5-10-year old children require more language experience to equilibrate comprehension and production abilities in grammatical processing of verbs. The difference between adults and children in Spanish, in both balanced and Spanish-dominant bilingual groups, was due to ceiling performance in adults in both 


\section{VULNERABILITIES IN GRAMMATICAL PROCESSING OF BILINGUALS}

comprehension and production (see Figure 1); children, on the other hand, performed worse in both modalities with production slightly outperforming comprehension.

The apparent discrepancies between our results and those of Gershkoff-Stowe and Hahn's (2013) study (showing that both children and adults exhibited the same size of gap, with an advantage for comprehension) can be attributed to differences in the cognitive processes involved in the performed tasks. Novel word learning, assessed in Gershkoff-Stowe and Hahn's study, relies on declarative memory, whereas grammatical processing, assessed in our study, relies on procedural memory (Ullman, 2016). More research comparing adults and children, performing lexical and grammatical tasks, in both production and comprehension, is needed in order to better understand how age modulates bilingual performance across various cognitive tasks (also argued in Finn et al., 2016).

\subsection{Morphological complexity}

\subsubsection{Subject-verb agreement}

Language-specific morphophonological properties affect children's subject-verb agreement acquisition, with, for instance, phonologically more salient agreement forms being processed more easily than less salient forms in comprehension (Legendre et al., 2014). In our study, we tested the impact of language-specific morphological properties on bilingual children and adults' expressive-receptive grammatical verb processing, in Spanish and Basque, in subject-verb and object-verb agreement contexts. In line with previous studies, we expected a larger gap for plural agreement as compared to singular, with comprehension outperforming production.

For children and in subject-verb agreement processing, our results partially confirmed our predictions: there was a larger gap in plural than in singular agreement in Basque, however, the opposite pattern was found in Spanish (see Figure 2), where a larger gap in singular agreement was observed, with an advantage for production. To understand the details 


\section{VULNERABILITIES IN GRAMMATICAL PROCESSING OF BILINGUALS}

of our results, it is important to consider the results in production and comprehension separately.

Previous studies on subject-verb agreement comprehension in Spanish have shown an advantage for plural forms in comparison to singular forms (Pérez-Leroux, 2005). In our study, a comparison of the data in the singular and the plural conditions also reveals that the scores in comprehension were better in plural than in singular subject-verb agreement (see Table 4: $89 \%$ vs $75 \%$ correct in Spanish-dominant bilingual children; $95 \%$ and $81 \%$ correct in balanced bilingual children, respectively; see also Appendix F). On the other hand, only a few errors were found in the production of plural agreement in Spanish. And since plural agreement processing is neither vulnerable in production nor in comprehension, the gap is almost non-existent, as reflected in Figure 2. However, singular agreement was performed worse in comprehension than in production, in both balanced and Spanish-dominant bilingual groups (see Spanish scores in Table 4: $93 \%$ vs $81 \%$, and $88 \%$ vs $75 \%$, respectively), thus explaining the observed advantage for production in Spanish (see Figure 2).

The comprehension disadvantage for singular agreement found in our study has been observed in other languages too (Johnson et al., 2005) and was attributed to the phonological salience of morphemes, which affects comprehension but has no impact on production and may lead to opposite patterns across languages (e.g., in Spanish vs. English). Our study supports the role of morphological aspects in language production and comprehension and shows that the gap is influenced by the morphological properties of the verb agreement systems and does not necessarily favor comprehension or singular agreement forms. In Basque, results on subject-verb agreement processing indicate a different pattern with an advantage for comprehension over production and for singular over plural agreement processing in children but not in adults. In adults, most errors were lexical in production explaining why errors were also found in singular contexts. In the following sub-section, we 


\section{VULNERABILITIES IN GRAMMATICAL PROCESSING OF BILINGUALS}

will further discuss to what extent the gap is language specific and related to the morphological properties of verb agreement systems.

\subsubsection{Object-verb agreement}

We tested whether the expressive-receptive gap in Basque was bigger in plural than in singular object-verb agreement in children and adults. This hypothesis (H4) stemmed from previous studies on subject-verb agreement showing that plural agreement is more problematic than singular agreement in production but not necessarily in comprehension (Verhagen, J., \& Blom, E., 2014). Our results align with this hypothesis: the gap was bigger in plural than in singular object-verb agreement and it was bigger in children than in adults. Although, note that in adults the gap between singular and plural forms was not significant. Interestingly, as can be seen from Figure 4, the gap with plural forms exhibited a clear advantage for comprehension showing that plural object-verb agreement was more prone to error in production than singular object-verb agreement (see also Anderson et al., to appear). Moreover, the phonological salience hypothesis could explain more difficulties with the plural as compared to the singular object-verb agreement for transitive verbs but not for ditransitive verbs (see Table 3, compare singular: $d u$ /du/ with plural ditu/ditu/ and singular dio /dio/ with plural die /die/, respectively), as the latter verbs have similar phonological complexity between agreement forms. More research is needed to determine why, despite a comparable level of phonological complexity, some inflected verbs are produced and understood better than others.

\section{Limitations of the study}

In this study, we opted for the use of intransitive and ditransitive verbs, with the aim of assessing verb agreement processing from a cross-language perspective in Basque and Spanish, because the Basque -not the Spanish- verb agreement paradigm overtly varies with verb transitivity. However, these verbs led to more lexical errors than transitive verbs. We 


\section{VULNERABILITIES IN GRAMMATICAL PROCESSING OF BILINGUALS}

decided to count the use of other verbs as an error because this led to the production of another agreement form in Basque, which reflected processing of a qualitatively different grammatical structure and could not be directly compared to the results in the comprehension task. More studies, carefully disentangling lexical and grammatical errors and/or adapting a fine-grained coding system, are needed in order to get a clearer picture of Basque-Spanish bilingual adults' grammatical abilities in production. This problem could be avoided either by not counting them as errors in future studies and revising the scoring system, or by only using transitive verbs with singular and plural subjects and objects. However, given the low number of such response types ( $4 \%$ of total $13 \%$ of errors), counting them as errors did not affect the significance of the main results.

Finally, although the difference in age between bilingual groups was not significant within each group, the age range was heterogeneous. Also, note that language exposure was estimated using questionnaires, where participants reported their language habits and those of their children (for the group of bilingual children). However, parents might over/underestimate language use by their children. For instance, a recent study suggests that, in Basque medium schools, children use Spanish during breaks and outdoor activities (Arrue project, 2013). More fine-grained questionnaires on language use and exposure, including various communicative settings (at school, in family, leisure activities etc.), are needed in order to measure language exposure as close as possible to natural language use and a bigger sample size is required in order to draw stronger conclusions about language processing in bilinguals.

\section{Conclusion}

This study examined bilinguals' expressive and receptive abilities in verb grammatical processing in typologically different languages, Basque and Spanish, and assessed the factors that might modulate them, i.e., age, exposure and language morphological complexity. Balanced Basque-Spanish and Spanish-dominant bilingual adults and children were assessed 


\section{VULNERABILITIES IN GRAMMATICAL PROCESSING OF BILINGUALS}

on their comprehension and production of subject- and object-verb agreement forms.

Consistent with the studies on bilinguals' lexical processing (Yan \& Nicoladis, 2009; Gibson, Oller, Jarmulowicz, \& Ethington, 2012), we found an expressive-receptive gap in bilinguals' grammatical processing. The gap size was modulated by language (Basque $>$ Spanish), age (children>adults) and agreement type (singular $>$ plural for Spanish, and singular $<$ plural for Basque), suggesting that language-specific morphological properties modulate and interact with the amount of expressive-receptive gap in grammatical processing of bilinguals. On the other hand, differences of exposure did not influence the gap size in Spanish, between the two bilingual groups (Basque-Spanish balanced and Spanish-dominant), which is at odds with the language exposure hypothesis (see Keller et al., 2015). This suggests that, in a context of officially coexisting languages, even less than 50\% exposure (to Spanish) is enough for accurate grammatical acquisition. However, bilinguals with relatively high exposure (more than $50 \%$ ) to one language (Basque) may struggle with its grammar if the language is richer and substantially different from the other language's morphological paradigm. In sum, our results show that language typology and the sociolinguistic environment influence bilinguals' grammatical expressive and receptive abilities and in general, this study adds new data to a growing body of research on the expressive-receptive gap in bilingual lexical processing and challenge psycholinguistic models of shared mechanisms for language production and comprehension.

\section{Acknowledgments}

The authors acknowledge financial support from the H2020 Marie Skłodowska-Curie Actions (FP7-PEOPLE-2011-IOF) awarded to the first author, and from the Spanish Ministry of Economy and Competitiveness, through the Severo Ochoa Programme for Centres/Units of Excellence in R\&D (SEV-2015-490) awarded to the Basque Centre on Cognition, Brain and 


\section{VULNERABILITIES IN GRAMMATICAL PROCESSING OF BILINGUALS}

Language. The authors are grateful to everyone who contributed to the realization of this study: Roxane Verville, Karen Schomecker, Goizalde Galartza, Edith Lebel, Phaedra Royle, Ecole d'Orthophonie et d'Audiologie de l'Université de Montréal, for their participation in the development of the fLEX tool, conceptualized and developed by the first author and programmed by the second author; Amaia Rodriguez, Mamen Gonzalez, Escuela Sagrada Corazon, Larraitz López, the Basque Centre on Cognition, Brain and Language, for the recruitment and assessment of Basque-Spanish adults and children; and special thanks to all participants. The authors are also very grateful to Paul Goldsmid for proofreading the manuscript and the anonymous reviewers for their helpful suggestions and insightful comments on earlier versions of the manuscript.

\section{References}

Ågren, M., \& van de Weijer, J. (2013). Number problems in monolingual and bilingual French-speaking children: A production/comprehension divide. Language, Interaction and Acquisition, 4, 25-50.

Anderson, Giezen and Pourquié, to appear. Basque-Spanish bilingual children's expressive and receptive grammatical abilities. Linguistic Approaches to Bilingualism, Special Issue on Psycholinguistic approaches to production and comprehension in bilingual adults and children .

Armon-Lotem, S., de Jong, J., \& Meir, N. (2015). Assessing multilingual children disentangling bilingualism from language impairment. Bristol; Buffalo: Multilingual Matters. Department of Education, Language Policy and Culture of the Basque Government and Sociolinguistics cluster (2013). Arrue Project. Retrieved from http://www.soziolinguistika.eus/arrue Bastiaanse, R. (2008). Production of verbs in base position by Dutch agrammatic speakers: 


\section{VULNERABILITIES IN GRAMMATICAL PROCESSING OF BILINGUALS}

Inflection versus finiteness. Journal of Neurolinguistics, 21(2), 104-119.

https://doi.org/10.1016/j.jneuroling.2006.10.006

Bastiaanse, R., Rispens, J., Ruigendijk, E., Rabadán, O. J., \& Thompson, C. K. (2002). Verbs: some properties and their consequences for agrammatic Broca's aphasia. Journal of Neurolinguistics, 15(3-5), 239-264. https://doi.org/10.1016/S0911-6044(01)00032-X

Bates, D. M., Mächler, M., Bolker, B., \& Walker, S. (2015). Fitting Linear Mixed-Effects Models Using lme4. Journal of Statistical Software, 67(1), 1-40.

Ben Zeev S. The influence of bilingualism on cognitive strategy and cognitive development. Child Development, 48, 1009-1018.

Blom, E., Vasić, N., \& Jong, J. de. (2014). Production and Processing of Subject-Verb Agreement in Monolingual Dutch Children With Specific Language Impairment. Journal of Speech, Language, and Hearing Research, 57(3), 952-965.

https://doi.org/10.1044/2014_JSLHR-L-13-0104

Bohman, T. M., Bedore, L. M., Peña, E. D., Mendez-Perez, A., \& Gillam, R. B. (2010). What you hear and what you say: language performance in Spanish-English bilinguals. International Journal of Bilingual Education and Bilingualism, 13(3), 325-344. https://doi.org/10.1080/13670050903342019

Finn, A. S., Kalra, P. B., Goetz, C., Leonard, J. A., Sheridan, M. A., \& Gabrieli, J. D. E. (2016). Developmental dissociation between the maturation of procedural memory and declarative memory. Journal of Experimental Child Psychology, 142, 212-220. https://doi.org/10.1016/j.jecp.2015.09.027

Franck, J., Cronel-Ohayon, S., Chillier, L., Frauenfelder, U. H., Hamann, C., Rizzi, L., \& Zesiger, P. (2004). Normal and pathological development of subject-verb agreement in speech production: a study on French children. Journal of Neurolinguistics, 17, 147-180. Franco, L. (2014). The lexical/functional divide in aphasic production: poorly studied aphasic 


\section{VULNERABILITIES IN GRAMMATICAL PROCESSING OF BILINGUALS}

syndromes and theoretical morpho-syntax: a collection of case studies in Italian.

Gershkoff-Stowe, L., \& Hahn, E. R. (2013). Word comprehension and production asymmetries in children and adults. Journal of Experimental Child Psychology, 114, 489-509.

Gibson, T. A., Oller, D. K., Jarmulowicz, L., \& Ethington, C. A. (2012). The receptiveexpressive gap in the vocabulary of young second-language learners: Robustness and possible mechanisms. Bilingualism: Language and Cognition, 15(1), 102-116.

Gibson, T. A., Peña, E. D., \& Bedore, L. M. (2014). The Receptive-Expressive Gap in Bilingual Children With and Without Primary Language Impairment. American Journal of Speech-Language Pathology, 23(4), 655-667. https://doi.org/10.1044/2014_AJSLP-12-0119 Gollan, T. H., Montoya, R. I., Cera, C., \& Sandoval, T. C. (2008). More use almost always means a smaller frequency effect: Aging, bilingualism, and the weaker links hypothesis. Journal of Memory and Language, 58(3), 787-814.

Gollan, T. H., Slattery, T. J., Goldenberg, D., Van Assche, E., Duyck, W., \& Rayner, K. (2011). Frequency drives lexical access in reading but not in speaking: The frequency-lag hypothesis. Journal of Experimental Psychology: General, 140(2), 186.

Gonzalez-Gomez, N., Hsin, L., Culbertson, J., Barrière, I., Nazzi, T., \& Legendre, G. (2014). Revealing early comprehension of subject-verb agreement in Spanish. In Boston University Language Development Conference 38 Proceedings (pp. 158-70). Retrieved from http://krieger.jhu.edu/cogsci/wp-content/uploads/sites/70/2017/02/Gonzalez-Gomez-et-al.BUCLD38-Proceedingscompressed3.pdf

Hualde, J. I., \& Zuazo, K. (2007). The standardization of the Basque language. Language Problems and Language Planning, 31(2), 143-168. https://doi.org/10.1075/1plp.31.2.04hua Hualde, J. I., and Ortiz de Urbina, J. (eds.). (2003). A Grammar of Basque. Mouton de Gruyter: Berlin.

Johnson, V. E., de Villiers, J. G., \& Seymour, H. N. (2005). Agreement without 


\section{VULNERABILITIES IN GRAMMATICAL PROCESSING OF BILINGUALS}

understanding? The case of third person singular/s/. First Language, 25(3), 317-330.

https://doi.org/10.1177/0142723705053120

Keller, K., Troesch, L. M., \& Grob, A. (2015). A large receptive-expressive gap in bilingual children. Frontiers in Psychology, 6, 10-3389.

Lapointe, S. G. (1985). A theory of verb form use in the speech of agrammatic aphasics.

Brain and Language, 24(1), 100-155. https://doi.org/10.1016/0093-934X(85)90100-2

Legendre, G., Culbertson, J., Zaroukian, E., Hsin, L., Barrière, I., \& Nazzi, T. (2014). Is

children's comprehension of subject-verb agreement universally late? Comparative evidence from French, English, and Spanish. Lingua, 144, 21-39.

https://doi.org/10.1016/j.lingua.2013.05.004

Lenth, R. V. (2016). Least-Squares Means: The R Package 1smeans. Journal of Statistical Software, 69(1), 1-33. https://doi.org/doi:10.18637/jss.v069.i01

Leonard, L. B. (2014). Specific Language Impairment Across Languages. Child Development Perspectives, 8(1), 1-5. https://doi.org/10.1111/cdep.12053

Litcofsky, K. A., Tanner, D., \& van Hell, J. G. (2016). Effects of language experience, use, and cognitive functioning on bilingual word production and comprehension. International Journal of Bilingualism, 20(6), 666-683.

Oller, D. K., Pearson, B. Z., \& Cobo-Lewis, A. B. (2007). Profile effects in early bilingual language and literacy. Applied Psycholinguistics, 28(2).

https://doi.org/10.1017/S0142716407070117

Pérez-Leroux, A. T. (2005). Number problems in children. In C. Gurski (Ed.), Proceedings of the 2005 Canadian Linguistic Association Annual Conference. London, Canada. Retrieved from http://westernlinguistics.ca/Publications/CLA-ACL/CLA-ACL2005.htm

Pickering, M. J., \& Garrod, S. (2014). Neural integration of language production and comprehension. Proceedings of the National Academy of Sciences, 111(43), 15291-15292. 


\section{VULNERABILITIES IN GRAMMATICAL PROCESSING OF BILINGUALS}

R Core Team. (2013). R: A Language and Environment for Statistical Computing. Vienna, Austria: R Foundation for Statistical Computing. Retrieved from http://www.R-project.org/ Pourquié, M. (2015). fLEX: Multilingual assessment of inFlectional and LEXical processing, Software, Intelectual property, 2016-01-88, Basque government.

Pourquié, M. (2013). Verb processing in Basque and French agrammatic aphasia: A 'postlexical access' deficit. Aphasiology, Volume 27(12):1472-1510.

Rothweiler, M., Chilla, S., \& Clahsen, H. (2012). Subject-verb agreement in Specific Language Impairment: A study of monolingual and bilingual German-speaking children. Bilingualism: Language and Cognition, 15(1), 39-57.

https://doi.org/10.1017/S136672891100037X

Ullman, M. T. (2016). The Declarative/Procedural Model: A Neurobiological Model of Language Learning, Knowledge, and Use. In G. Hickok \& S. L. Small (Eds.), Neurobiology of Language (pp. 953-968). San Diego: Academic Press. https://doi.org/10.1016/B978-0-12407794-2.00076-6

Verhagen, J., \& Blom, E. (2014). Asymmetries in the acquisition of subject-verb agreement in Dutch: Evidence from comprehension and production. First Language, 34(4), 315-335. https://doi.org/10.1177/0142723714544412

Waxman, S., Fu, X., Arunachalam, S., Leddon, E., Geraghty, K., \& Song, H. (2013). Are Nouns Learned Before Verbs? Infants Provide Insight Into a Long-Standing Debate. Child Development Perspectives, 7(3), 155-159. https://doi.org/10.1111/cdep.12032 Yan, S., \& Nicoladis, E. (2009). Finding le mot juste: Differences between bilingual and monolingual children's lexical access in comprehension and production. Bilingualism: Language and Cognition, 12(3), 323-335. 